\title{
Herbivore-mediated increase in the photosynthetic capacity of marine biofilms: indirect effects of changing microalgal assemblage composition
}

\author{
S. Kaehler*, P. W. Froneman \\ Coastal Research Group, Department of Zoology and Entomology, Rhodes University, PO Box 94, Grahamstown 6140, \\ South Africa
}

\begin{abstract}
The effects of grazing by the high-shore periwinkle Nodilittorina africana on the biomass, productivity, composition and diversity of microalgal assemblages were experimentally assessed on the south coast of South Africa. The results indicate that littorinids selectively removed large/filamentous and loosely attached 'overstorey' cyanobacteria, thereby reducing microalgal biomass and species diversity. As grazers also eliminated macroalgal sporelings, they restricted the upper distributional limit of Ulva spp. and Enteromorpha spp., which in the absence of grazers colonized and persisted on the high shore. The grazing-induced reduction in algal biomass resulted in a decline in overall biofilm productivity (production $\mathrm{cm}^{-2}$ ). In contrast, the photosynthetic capacity of algae (production per $\mu \mathrm{g}$ chlorophyll a) increased in grazed plots. This latter observation could be explained neither by nutrient addition from molluscan excretions in exclusion plots (mechanical disturbance induced photosynthetic capacity) nor by nutrient/light limitation in ungrazed plots (treatment effect was significant in biofilms of similar thickness). Instead, the results indicate that the physical disturbance caused by littorinid grazing changes the composition of microalgal assemblages to one dominated by more productive taxa.
\end{abstract}

KEY WORDS: Biofilm $\cdot$ Grazing $\cdot$ Productivity $\cdot$ Biomass $\cdot$ Microalgal composition

\section{INTRODUCTION}

While erect macroalgae are often the most conspicuous primary producers on rocky shores, many intertidal herbivores (e.g. taenioglossan and rhipidoglossan molluscs) feed on microscopic forms that include the microalgae, cyanobacteria as well as microscopic germlings of seaweeds (Hawkins et al. 1989, Norton et al. 1990). The organisms constituting this epilithic biofilm are especially important to herbivores on the high shore, where they are often the dominant primary pro-

*E-mail: s.kaehler@ru.ac.za ducers. Nonetheless, with a few notable exceptions (see following paragraph), the interactions between herbivores and marine epilithic microalgal communities are largely unexplored (Underwood 1984, Hillebrand et al. 2000, Williams et al. 2000).

Most information available on the grazing of epibenthic microalgal communities originates from freshwater studies. A comparatively large number of investigations have shown that, in freshwater habitats, grazers can control microalgal biomass, affect productivity and species richness, and change the composition of the biofilm (e.g. Hargrave 1970, Cooper 1973, Hunter 1980, Lowe \& Hunter 1988, Swamikannu \& Hoagland 1989, McCormick \& Stevenson 1991, Steinman et al. 1991, 
Rosemond et al. 1993). In contrast, marine studies have in the past focused primarily on the effects of grazers on microalgal biomass and composition (Castenholz 1961, Nicotri 1977, Hunter \& Russell-Hunter 1983, Mak \& Williams 1999, Williams et al. 2000). Although there are some suggestions that marine grazers may also affect biofilm productivity (Hunter \& RussellHunter 1983) and diversity (Hillebrand et al. 2000), there is as yet little direct evidence for these propositions and no single study has investigated the potential effects of grazers in unison.

The current study aimed to experimentally assess the effects of the periwinkle Nodilittorina africana on the biomass, productivity, composition and diversity of high-shore microalgal assemblages. As molluscan grazing may theoretically affect microalgal assemblages both by physically removing parts of the biofilm and by addition of nutrients, the mechanical aspect of grazing was further investigated by simulating microalgal removal by herbivores with a soft brush.

\section{MATERIALS AND METHODS}

Study site. All experimental manipulations were carried out on a high-shore sandstone platform in Waterloo Bay $\left(33^{\circ} 30^{\prime} \mathrm{S}, 27^{\circ} 10^{\prime} \mathrm{E}\right)$ approximately $3 \mathrm{~km}$ east of the Great Fish River mouth (Eastern Province, South Africa). At the study location, Nodilittorina africana was the only grazer observed during low tide and occurred at densities of up to 300 individuals $\mathrm{m}^{-2}$.

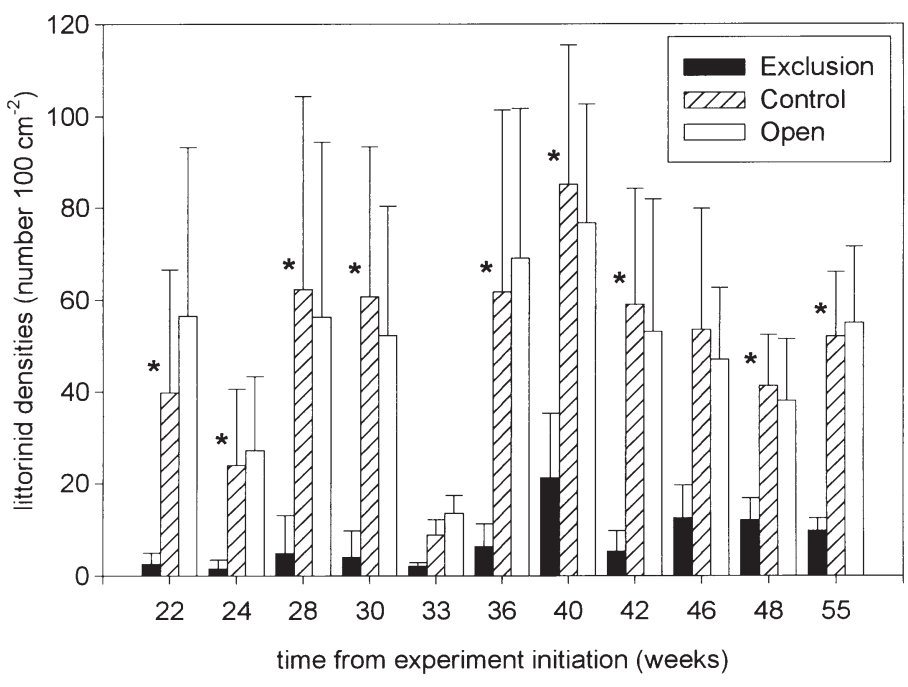

Fig. 1. Nodilittorina africana. Mean $( \pm \mathrm{SD})$ densities in the 3 grazer manipulation treatments over time. At no time of the experiment were Control (i.e. controls for possible paint effects) and Open (i.e. unmanipulated) plots significantly different; *significantly greater densities in Exclusion plots (Tukey test; $\mathrm{p}<0.05$ )
Siphonaria serrata and S. capensis occurred slightly lower on the shore but, due to the gentle slope of the platform, were located several meters away from the experimental area. Macroalgae were extremely rare and restricted to the occasional occurrence of Porphyra capensis. Most of the rock appeared bare, but was covered by an epilithic biofilm that is likely to play an important role in providing food for the highly dense population of periwinkles.

Grazer manipulation. Grazer densities were manipulated to investigate their effects on algal biomass and productivity over a period of $55 \mathrm{wk}$. To exclude Nodilittorina africana from $25 \times 25 \mathrm{~cm}$ areas, a $5 \mathrm{~cm}$ wide copper-paint barrier (Interspeed BJA600, Plascon Paints Natal) was created around the experimental plots and all grazers from within were removed ('exclusion'). To maintain optimal exclusion, any newly immigrated/recruited grazers were removed from the exclusion plots during each of the following sampling sessions. Unmanipulated plots ('open') allowed natural grazer densities, whereas plots with half-length paint barriers allowed grazer access while acting as a procedural control for possible paint effects ('control'). In order to ensure adequate treatment dispersal, 1 plot of each of the 3 treatments was randomly positioned in each of 4 blocks ( 3 treatments $\times 4$ blocks $=12$ plots).

To confirm adequate exclusion or access of Nodilittorina africana in the 3 treatments, grazer densities in the plots were recorded during each sampling session from Week 22 onwards. With 2 exceptions (i.e. Weeks 33 and 46), N. africana densities were significantly lower in grazer manipulation plots (2-way ANOVA on treatment and time followed by Tukey's HSD test, Fig. 1 ; treatment: $\mathrm{df}=2, F=131.288, \mathrm{p}<0.0001$; time: $\mathrm{df}=10, F=8.199, \mathrm{p}<0.0001$; treatment $\times$ time: $\mathrm{df}=20$, $F=1.136, \mathrm{p}=0.326$ ) than in control or open plots. Control and open plots always contained similar grazer densities (no significant differences at any time). The grazer manipulation treatment effectively reduced the density of $N$. africana by $85.51 \pm 9 \%$ SD. It should be noted that while grazer manipulation did not totally eliminate all grazers, the term 'exclusion treatment' will be used for practical reasons throughout this paper.

To investigate the effect of grazers on algal biomass, 3 rock chips (natural substratum containing no visible macroalgal cover) were collected, at varying intervals, from each of the 12 plots using a hammer and chisel (typical chip size $<1 \mathrm{~cm}^{2}$ ). No area within the plots was sampled more than once. Chlorophyll $a$ and phaeopigment concentrations were determined fluorometrically after extraction in $90 \%$ acetone for $24 \mathrm{~h}$ (adapted from Parsons et al. 1984). Pigment concentrations were then determined from measurements of fluorescence taken before and after acidification, using a Turner Designs Model 10-AU fluorometer (Parsons et al. 1984). Chlo- 
rophyll a concentrations were standardized to $\mu \mathrm{g} \mathrm{cm}^{-2}$ after determining the surface area of rock chips using Sigmascan Image Analysis Software (Jandel Scientific) on outline traces.

Algal productivity was determined during 5 consecutive seasons by measuring $\left[{ }^{14} \mathrm{C}\right]$ sodium bicarbonate incorporation of the biofilm attached to rock chips sampled from each of the 12 plots (see above). Rock chips were placed into filtered seawater (0.45 $\mu \mathrm{m}$ Millipore filter), in $250 \mathrm{ml}$ light-neutral polycarbonate incubation bottles and spiked with $25 \mu \mathrm{Ci}$ sodium bicarbonate. In order to facilitate comparisons of production values between times, incubations were conducted under uniform conditions in a light box (for $4 \mathrm{~h}$ at PAR $\approx$ $130 \mu \mathrm{mol} \mathrm{m} \mathrm{m}^{-2} \mathrm{~s}^{-1}$ ) rather than under variable field conditions. After incubation, rock chips were submersed in $3 \mathrm{M} \mathrm{HCl}$ to remove any unincorporated ${ }^{14} \mathrm{C}$. The rock chips were then placed into high-performance scintillation vials to which $20 \mathrm{ml}$ Ultima Gold Fluor was added. Disintegrations per minute (dpm) were recorded after $24 \mathrm{~h}$ using a Beckman liquid scintillation counter. ${ }^{14} \mathrm{C}$ incorporation into algal tissues was

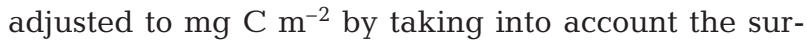
face area of the rock chips. As incubation occurred under artificial light, actual in situ production values were not determined. Instead, calculated values should be viewed as relative estimates of potential production and be used primarily for comparisons between seasons and treatments.

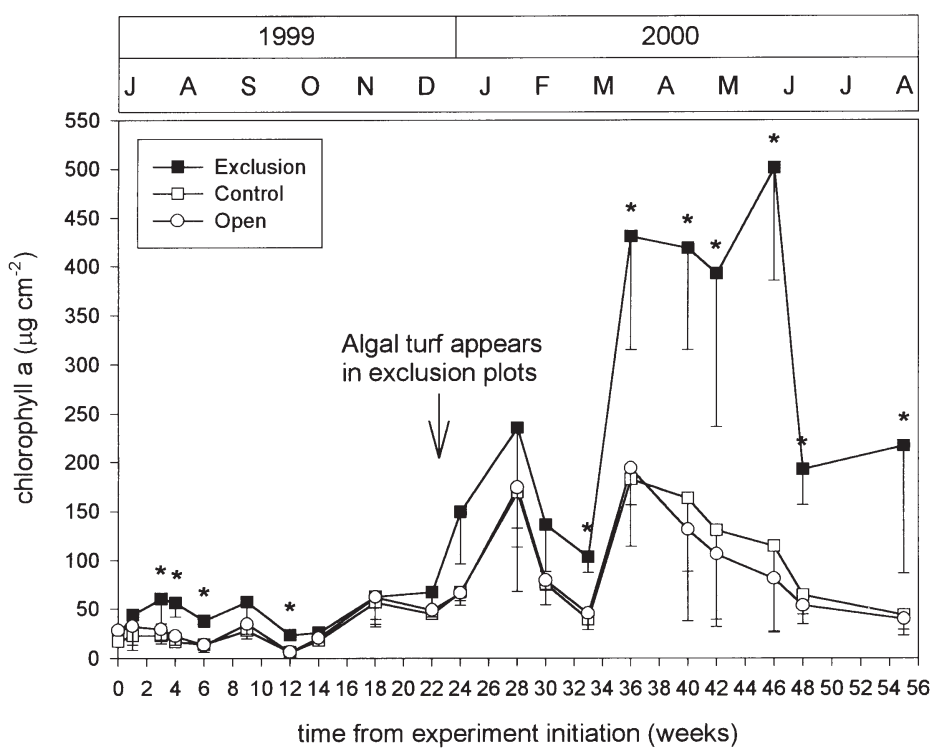

Fig. 2. Mean $( \pm \mathrm{SD})$ microalgal biomass in the absence (Exclusion) and presence (Control and Open) of Nodilittorina africana for the duration of the experiment. At no time of the experiment were Control and Open plots significantly different; *significantly greater biomass in absence of herbivores (Tukey test; $\mathrm{p}<0.05$ )
Biofilm composition and diversity. To determine whether grazing affected the community composition of the biofilm, during Week 55 one rock chip (without visible macroalgal cover) was collected from each of the 12 plots. From each rock chip, 3 scrapings were taken with a scalpel and transferred onto microscope slides for observation under a fluorescence microscope (Olympus BX60, WG cube, 200× magnification). The percentage composition of the biofilm was estimated by scoring the occurrence of different algal taxa under a 100 point ocular grid for each of the 36 scrapings. Shannon-Wiener and reciprocal Simpson diversity indices were then calculated for each individual plot (Krebs 1989). The most abundant microalgal species were identified by S. Nagarkar and G. A. Williams (University of Hong Kong).

Biofilm manipulation. Possible mechanisms involved in the grazer-induced change in algal productivity and composition (see 'Results') were studied by investigating the effects of physical disturbance of the biofilm, in newly created exclusion plots $(\mathrm{n}=10)$. In order to simulate the mechanical effect of grazing, half the plots $(n=5)$ were stroked with a soft nailbrush every third day for $3 \mathrm{wk}$, effectively removing some of the microalgae (brushed treatment). The other 5 exclusion plots were left unmanipulated (unbrushed treatment), providing base-line chlorophyll, productivity and composition data for ungrazed plots. After $3 \mathrm{wk}$, 3 rockchips each were removed from every plot for productivity measurements, chlorophyll a determination and microscopic investigation. Methods for the analyses were identical to those in the grazer manipulation experiment.

Data analyses. Statistical analyses were performed using Statistica 5.5 (Statsoft). ANOVAs were used to test for treatment effects on chlorophyll $a$, productivity and diversity. In order to test for treatment effects on the relationship between chlorophyll $a$ and productivity (photosynthetic capacity), ANCOVAs were performed. Tukey multiple-comparison tests were performed to further investigate significant differences (biologically relevant results are shown in Figs. 1 to 5 \& 7 ).

\section{RESULTS}

\section{Biomass}

In the grazer manipulation experiment, microalgal biomass ( $\mu \mathrm{g}$ chlorophyll $\mathrm{a} \mathrm{cm}^{-2}$ ) was first significantly enhanced in exclusion plots 3 wk into the study (Fig. 2; ANOVA on herbivore treatment and time-treatment: $\mathrm{df}=2, F=201.473, \mathrm{p}<0.001$; time: $\mathrm{df}=19, F=101.401$, $\mathrm{p}<0.001$; interaction: $\mathrm{df}=38, F=4.115, \mathrm{p}<0.001)$. Overall, compared to exclusion plots, grazed treat- 


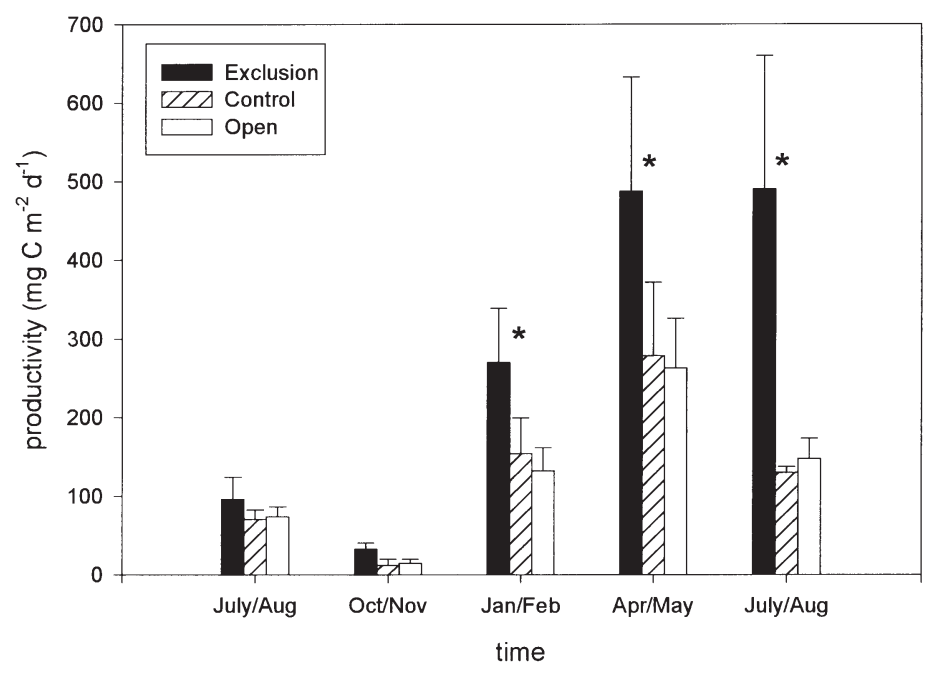

Fig. 3. Mean $( \pm \mathrm{SD})$ microalgal productivity in the absence (exclusion) and presence (Control and Open) of Nodilittorina africana during 5 sampling periods. At no time of the experiment were Control and Open plots significantly different; *significantly greater productivity in absence of herbivores (Tukey test; $\mathrm{p}<0.05$ )

ments exhibited significantly reduced microalgal biomass in 11 out of 19 sampling periods (Fig. 2). In contrast, microalgal biomass did not differ significantly at any time between control and open plots. Microalgal biomass varied significantly with time in all treatments, with peaks in the austral summer and autumn months and reduced biomass during winter and spring.

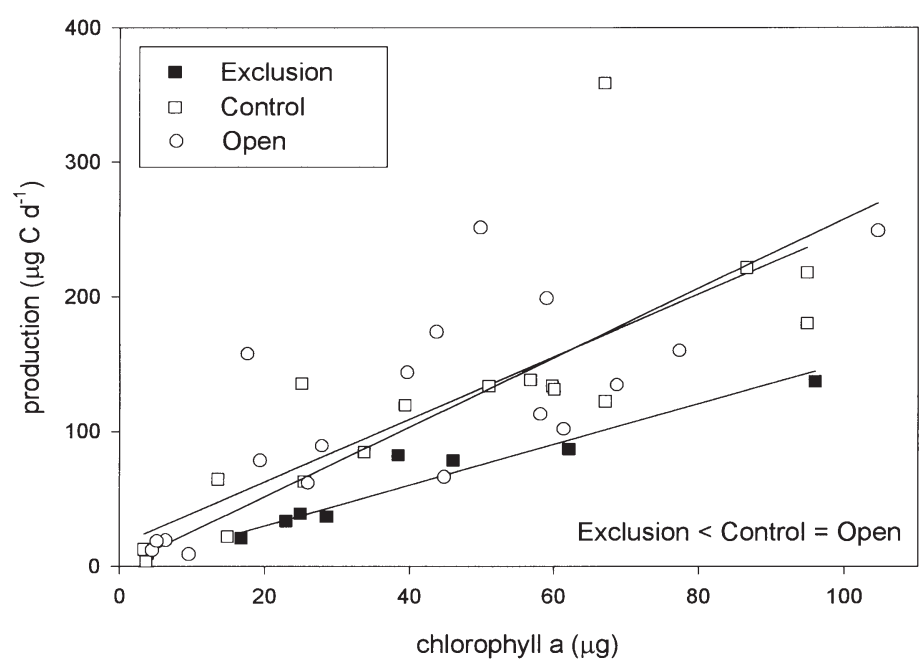

Fig. 4. Microalgal production in relation to microalgal biomass in the absence (Exclusion) and presence (Control and Open) of Nodilittorina africana. ANCOVA results indicate that photosynthetic capacity of microalgae (production per unit chlorophyll a) is higher in presence than in absence of the grazer (Tukey test; $\mathrm{p}<0.05$ ). At no time of the experiment were Control and Open plots significantly different
In addition to reducing microalgal biomass, grazers inhibited the establishment of macroalgae, which occurred exclusively in exclusion plots from Week 23 onwards (Fig. 2). Ulvoids (i.e. Ulva spp., Enteromorpha spp.) were at no time observed in the surrounding environment, but became established to varying degrees ( 30 to $80 \%$ cover) in all exclusion plots and persisted to the end of the experiment.

\section{Productivity}

Production estimates every 3 mo showed that microalgal productivity per unit area varied seasonally, and from January 2000 onwards was significantly greater in exclusion plots than in the presence of natural grazer densities (Fig. 3; 2-way ANOVA on herbivore treatment and time-treatment: $\mathrm{df}=2, F=36.128, \mathrm{p}<$ 0.001; time: $\mathrm{df}=4, F=88.934, \mathrm{p}<0.001$; treatment $\times$ time: $\mathrm{df}=8, F=4.109, \mathrm{p}=0.001$ ). When standardizing productivity against chlorophyll a (i.e. production per $\mu \mathrm{g}$ chlorophyll $=$ photosynthetic capacity), however, open/control plots exhibited greater production than did the exclusion plots (Fig. 4; ANCOVA on herbivore treatment with chlorophyll $a$ as covariate-treatment: $\mathrm{df}=2, F=5.494, \mathrm{p}=0.007)$. Thus, grazers reduced overall production on the shore (production per unit area) but increased the photosynthetic capacity of the biofilm. There was no significant difference in production or photosynthetic capacity between control and open plots.

When simulating the mechanical effects of grazing with a nail brush, after 3 wk the physically disturbed plots exhibited a greater photosynthetic capacity

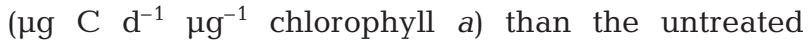
samples (Fig. 5; ANCOVA on treatment with chlorophyll as covariate: $\mathrm{df}=1, F=4.818, \mathrm{p}=0.036$ ).

\section{Biofilm composition and diversity}

Microscopic examination of the biofilm in grazed and exclusion plots revealed extreme differences in composition and diversity (Fig. 6). Exclusion plots contained 16 distinguishable taxa including a variety of filamentous and coccoid cyanobacteria and microscopic sporelings of macroalgae (Fig. 6C to F). The most abundant taxa, each contributing $>10 \%$ to total abundance, were Aphanocapsa sp., Gloeocapsa crepidinum, Chroococcus sp., Pleurocapsa sp. and Phormidium sp. Filamentous cyanobacteria and sporelings made up $>25 \%$ of the biofilm. In contrast, grazed plots (open and control) were dominated (>90\% cover) by the coccoid cyanobacteria Gloeocapsa pleurocapsoides and G. crepidinum (Fig. 6A,B). No filamentous cyano- 


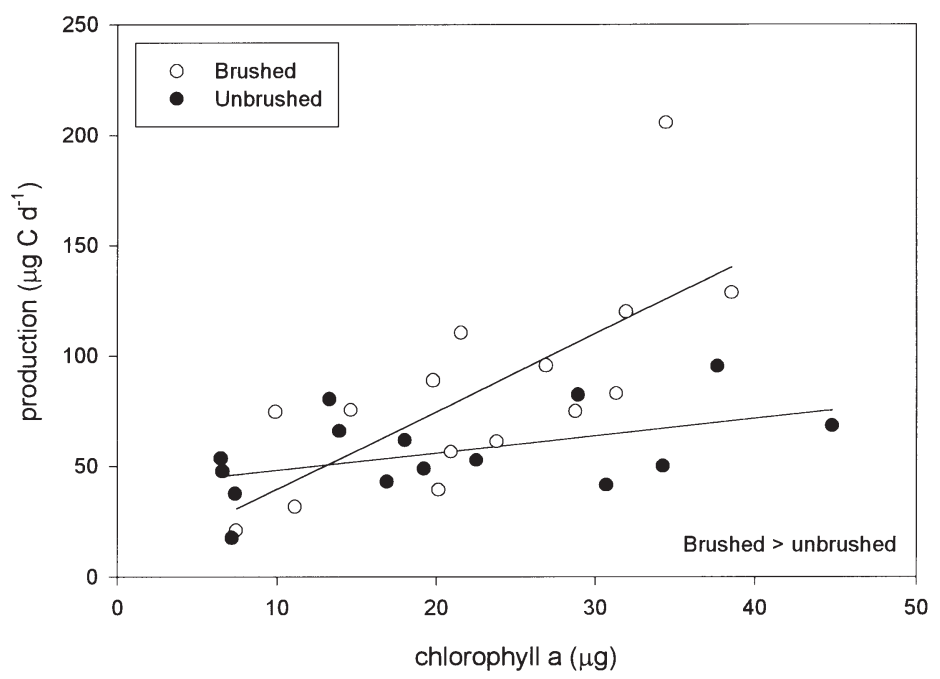

Fig. 5. Microalgal production in relation to microalgal biomass in artificially disturbed (Brushed) and undisturbed (Unbrushed) treatments. ANCOVA results indicate that photosynthetic capacity of microalgae (production per unit chlorophyll $a$ ) is higher in presence than in absence of the grazer $(\mathrm{p}=0.036)$

bacteria or sporelings of macroalgae were observed in open or control plots.

The brushing experiment yielded similar results to the grazer manipulation experiment. Unbrushed plots contained a total of 14 species with filamentous cyanobacteria and sporelings contributing $>30 \%$ to the biofilm. In contrast, brushed plots were dominated by Gloeocapsa pleurocapsoides and G. crepidinum, which together made up $>98 \%$ of total abundance.

Species diversity (Shannon-Wiener and reciprocal Simpson indices, Fig. 7) in both grazer manipulation and grazer simulation experiments was significantly lower in plots that had been physically disturbed (grazed or brushed) than in untreated plots (exclusion or unbrushed). ANOVAs followed by Tukey's HSD tests showed that grazer manipulation and unbrushed treatments always had higher diversity indices than open/control and brushed treatments (Fig. 7).

\section{DISCUSSION}

As has previously been shown, microalgal grazers were capable of significantly reducing the biomass of marine epilithic biofilms (e.g. Castenholz 1961, Nicotri 1977, Hunter \& Russell-Hunter 1983, Dye \& White 1991, Williams et al. 2000). More unusual was the observation that littorinids also restricted the establishment of erect seaweeds in the high littoral. In the absence of grazers, Ulva spp. and Enteromorpha spp. became established and persisted at a tidal height at which they had not been recorded previously. Littorinids limited the upper distributional limit of these species by eliminating microscopic germlings present in the biofilm. Unlike the vast majority of studies investigating upper distributional boundaries (reviews by Underwood \& Denley 1984 and Underwood 1991), physiological stress did not, therefore, seem to be of primary importance in restricting the distribution of macroalgae to lower tidal heights.

Grazers reduced biofilm biomass (chlorophyll a) during 11 out of 19 sampling periods by physically removing a large number of cyanobacteria and macroalgal sporelings from rock surfaces within the open and control treatments. Grazing, however, was selective in that the majority of sporelings, filamentous and large coccoid cyanobacteria were eliminated, while smaller coccoid species such as Gloeocapsa pleurocapsoides and G. crepidinum remained abundant in grazed treatments (see also Castenholz 1961, Nicotri 1977, Hunter \& Russell-Hunter 1983, Hillebrand et al. 2000). The larger and filamentous taxa that often form the loose overstorey of the biofilm are more easily removed by grazers than are the smaller, more closely attached coccoid cyanobacteria.

Nicotri (1977) was probably the first to suggest that selective grazing of intertidal microalgae was a primarily passive process, with the structure of the molluscan radula facilitating the removal of large chainforming morphologies while smaller, more tightly adherent taxa escape mechanical removal by the grazers (see also Hunter \& Russell-Hunter 1983, Hillebrand et al. 2000). It should be noted, however, that several non-molluscan grazers (e.g. isopods and insect larvae) have been shown to more actively select or avoid microalgal species according to their nutritional quality, physical characteristics or toxicity (Mullholland et al. 1991, Sommer 1997). The present study supports the passive selection hypothesis. While we have no data on the nutritional quality of the species comprising the biofilm, the grazer simulation experiment clearly showed that artificial mechanical disturbance results in a biofilm composition similar to that caused by the grazing activity of littorinids. Active selection by the grazers may, therefore, be ruled out as a major determinant of community composition.

As the littorinids removed the more easily accessible species from the overstorey of the biofilm, species diversity was significantly reduced. In contrast to the grazed plots, which were dominated by only 2 species (Gloeocapsa pleurocapsoides and G. crepidinum constituted $>90 \%$ of biofilm), ungrazed plots were significantly more diverse and contained up to 12 additional microalgal taxa. There are a number of studies (from marine and freshwater habitats) that illustrate the importance of grazing on the species richness of biofilms 

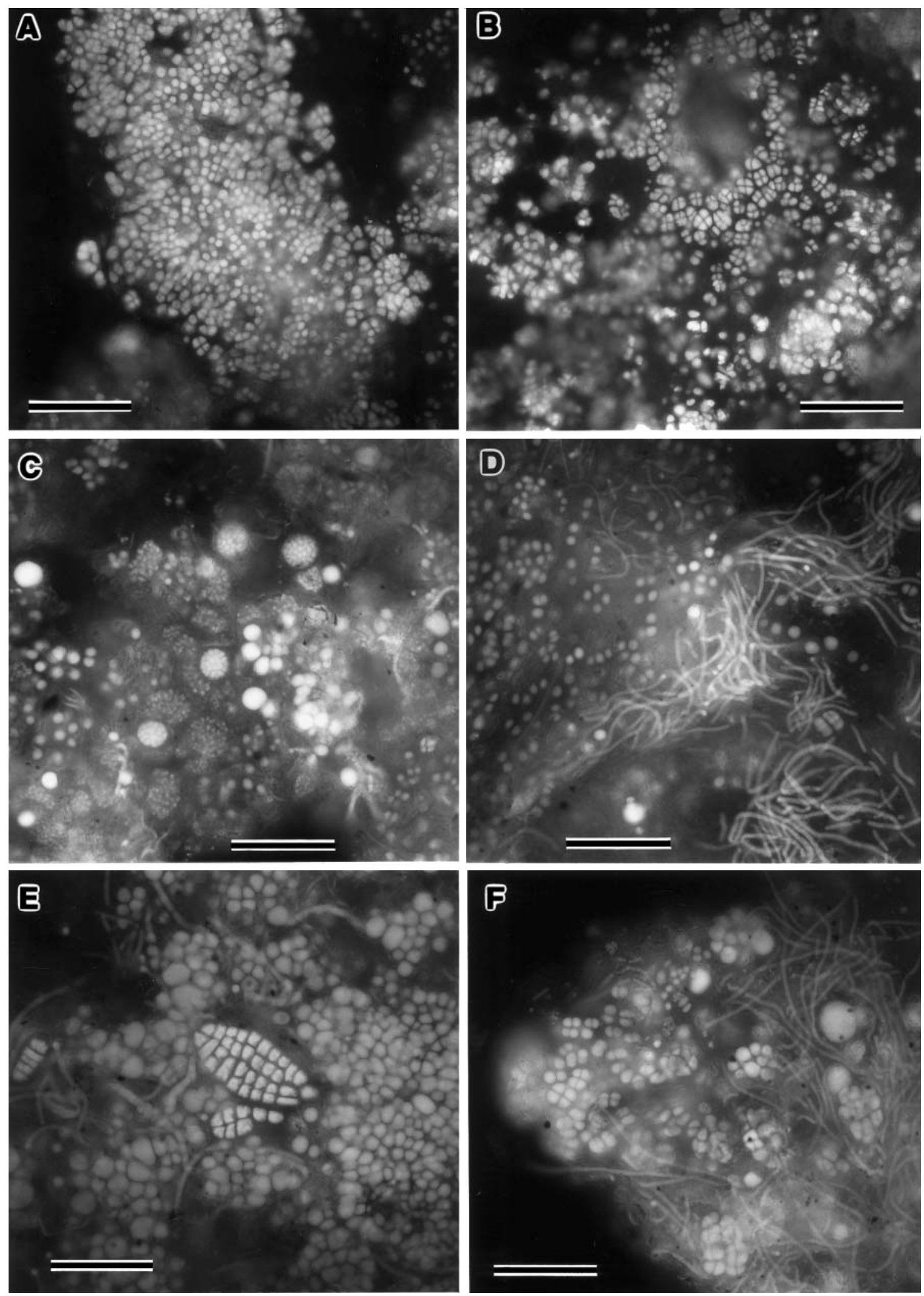

Fig. 6. Fluorescence micrographs of representative algal assemblages in grazed $(A, B)$ and ungrazed $(C$ to $F)$ treatments. Grazed assemblages were dominated by Gloeocapsa pleurocapsoides and G. crepidinum (A,B); ungrazed assemblages contained additional taxa such as Aphanocapsa spp. and Pleurocapsa sp. (C), Chroococcus sp. and Phormidium sp. (D), and Calothrix spp. and macroalgal sporelings (E), and included large and/or filamentous taxa. Scale bars $=50 \mu \mathrm{m}$ 

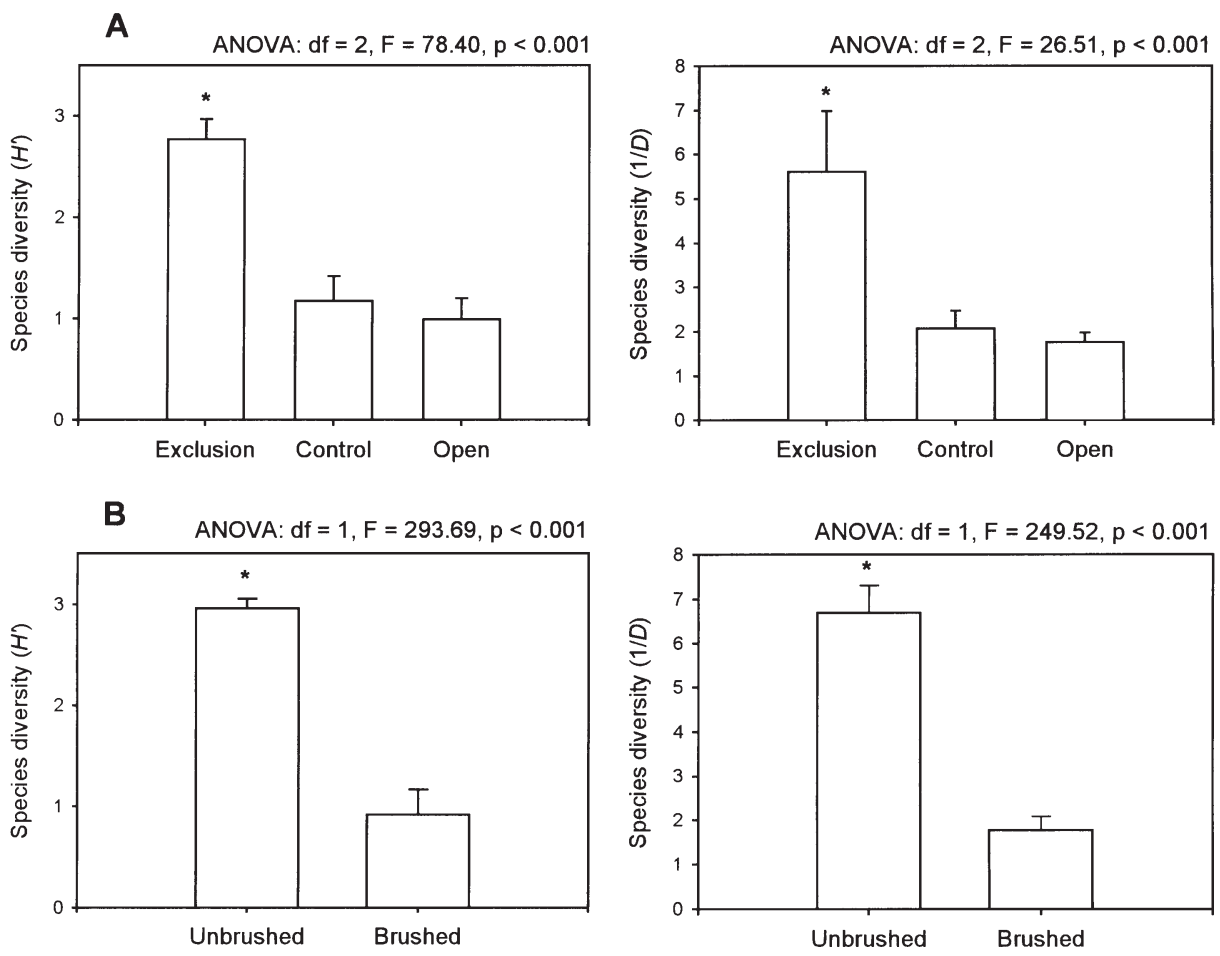

Fig. 7. Species diversity indices for grazer exclusion experiment (A) and grazer simulation experiment (B). *Significantly higher diversity in undisturbed treatments (Ungrazed or Unbrushed) than in disturbed treatments (Grazed or Brushed) (Tukey test; $\mathrm{p}<0.05)$. At no time of the experiment were Control and Open plots significantly different

(freshwater literature reviewed by Steinman 1996). The net effects of grazers, however, are inconsistent and at times contradictory, with grazers either reducing or enhancing species diversity and richness (Hunter \& Russell-Hunter 1983, Swamikannu \& Hoagland 1989, Hillebrand et al. 2000, Huchette et al. 2000).

A recent meta-analysis of grazing effects in terrestrial and aquatic habitats (Proulx \& Mazumder 1998) suggests that there is a trend of grazers reducing species richness in nutrient-poor ecosystems and enhancing species richness in nutrient-rich ecosystems ('grazer reversal hypothesis'). Proulx \& Mazumder (1998) furthermore argued that grazer-induced declines in species richness are most probably due to nutrient limitation preventing the regrowth of species after disturbance. While we have not quantified nutrient availability to the biofilm, the data on the photosynthetic capacity of cyanobacteria (see below) suggests that even understorey taxa of the biofilm were not nutrientlimited. It is likely, therefore, that the decline in species richness was directly related to the mechanical removal of a large number of loosely attached overstorey species, rather than to a nutrient effect.

Associated with the increase in microalgal biomass in the exclusion plots was an overall increase in biofilm productivity. While biofilm productivity was significantly greater in exclusion plots during only 3 of the 5 sampling periods, there was a trend of greater production in ungrazed plots (compared to grazed plots) for the whole duration of the experiment. This in itself is not surprising, as a larger number of photosynthetic organisms might be expected to fix more carbon. More interesting was the observation that the photosynthetic capacity of the biofilm (productivity per $\mu \mathrm{g}$ chlorophyll a) was higher in the grazed than in the ungrazed plots. The same result was obtained when artificially simulating grazing activity with a brush.

There are a variety of possible explanations for an increased photosynthetic capacity of the biofilm in the presence of grazers. A nutrient effect associated with molluscan excretions may be discounted, as both the grazed and artificially disturbed treatments resulted in a significant increase in photosynthetic capacity. Increased access to nutrients or light in the 'thinner' biofilm matrix of grazed plots could theoretically account for an increase in the photosynthetic capacity. It has previously been shown that grazers can mediate nutrient availability to the understorey of biofilms by removing overlying cells (McCormick \& Stevenson 1991). In the present study, however, algal productivity in grazed and ungrazed plots was significantly different even where algal biomass and (presumably) film thickness were similar. This suggests that the reduction in the photosynthetic capacity of cyanobacteria in ungrazed plots cannot have been due solely to nutrient or light limitation.

The most plausible explanation for the increase in the photosynthetic capacity of the biofilm is a grazerinduced change in assemblage composition to one dominated by more productive taxa. At first glance this may sound counterintuitive, as it is usually the slower- 
growing but physically/chemically defended species that survive intense grazing while faster-growing opportunistic species are removed. Nonetheless, where grazing acts as a severe disturbance, space may be made available which will facilitate the colonization and/or re-growth of fast-growing opportunistic taxa. In such a scenario, grazing would enhance the photosynthetic capacity of the biofilm by resetting the assemblage to an earlier successional state dominated by fast-growing opportunists. This suggestion is partially supported by the fact that, in a separate experiment, the dominant species in grazed plots, Gloeocapsa pleurocapsoides, was shown to be one of the first phototrophic organisms to colonize cleared substrata (P.W.F \& S.K. unpubl. data).

The current study suggests that by selectively removing the more easily ingested overstorey species of the biofilm, Nodilittorina africana reduces the biomass and species diversity of the high-shore biofilm and changes microalgal assemblages to assemblages dominated by more productive species. There was little evidence for nutrient or light limitation in any of the treatments, and mechanical grazing simulation resulted in similar algal communities to those grazed by $N$. africana. In contrast, therefore, to some freshwater studies, our results indicate that the grazing-induced changes in marine biofilm production were the indirect result of selective mechanical disturbance of the microalgal assemblages.

Acknowledgements. We would like to thank S. Nagarkar and G. A. Williams (University of Hong Kong) for identifying the cyanobacteria. This project was partly funded by a National Research Foundation postdoctoral fellowship to S.K. and a Joint Research Committee Grant (Rhodes University) to P.W.F.

\section{LITERATURE CITED}

Castenholz RW (1961) The effect of grazing on marine littoral diatom populations. Ecology 42:783-794

Cooper DC (1973) Enhancement of net primary productivity by herbivore grazing in aquatic laboratory microcosms. Limnol Oceanogr 18:31-37

Dye AH, White DRA (1991) Intertidal macroalgal production and molluscan herbivory in relation to season and elevation on two rocky shores on the east coast of southern Africa. S Afr J Sci 11:483-489

Hargrave BT (1970) The effect of a deposit-feeding amphipod on the metabolism of benthic microflora. Limnol Oceanogr 15:21-30

Hawkins SJ, Watson DC, Hill AS, Harding SP, Kyriakides MA, Hutchinson S, Norton TA (1989) A comparison of feeding mechanisms in microphagous, herbivorous, intertidal prosobranchs in relation to resource partitioning. J Molluscan Stud 55:151-165

Hillebrand H, Worm B, Lotze HK (2000) Marine microbenthic community structure regulated by nitrogen loading and grazing pressure. Mar Ecol Prog Ser 204:27-38

Huchette SMH, Beveridge MCM, Baird DJ, Ireland M (2000)

Editorial responsibility: Otto Kinne (Editor),

Oldendorf/Luhe, Germany
The impacts of grazing by tilapias (Oreocgromis niloticus L.) on periphyton communities growing on artificial substrate in cages. Aquaculture 186:45-60

Hunter RD (1980) Effects of grazing on the quantity and quality of freshwater Aufwuchs. Hydrobiologia 69:251-259

Hunter RD, Russell-Hunter WD (1983) Bioenergetic and community changes in intertidal Aufwuchs grazed by Littorina littorea. Ecology 64:761-769

Krebs CJ (1989) Ecological methodology. Harper Collins, New York

Lowe RL, Hunter RD (1988) Effect of grazing by Physa integra on periphyton community structure. J N Am Benthol Soc 7:29-36

Mak YM, Williams GA (1999) Littorinids control high intertidal biofilm abundance on tropical, Hong Kong rocky shores. J Exp Mar Biol Ecol 233:81-94

McCormick PV, Stevenson RJ (1991) Grazer control of nutrient availability in the periphyton. Oecologia 86:287-291

Mullholland PJ, Steinman AD, Palumbo AV, Elwood JW, Kitchell DB (1991) Role of nutrient cycling and herbivory in regulating periphyton communities in laboratory streams. Ecology 72:966-982

Nicotri ME (1977) Grazing effects of four marine intertidal herbivores on the microflora. Ecology 58:1020-1032

Norton TA, Hawkins SJ, Manley NL, Williams GA, Watson DC (1990) Scraping a living: a review of littorinid grazing. Hydrobiologia 193:117-138

Parsons TR, Mayta Y, Lalli CM (1984) A manual of chemical and biological methods for seawater analysis. Pergamon Press, Oxford

Proulx M, Mazumder A (1998) Reversal of grazing impact on plant species richness in nutrient-poor vs. nutrient-rich ecosystems. Ecology 79:2581-2592

Rosemond AD, Mulholland PJ, Elwood JW (1993) Top-down and bottom-up control of stream periphyton: effects of nutrients and herbivores. Ecology 74:1264-1280

Sommer U (1997) Selectivity of Idothea chelipes (Crustacea: Isopoda) grazing on benthic microalgae. Limnol Oceanogr 42:1622-1628

Steinman AD (1996) Effects of grazers on freshwater benthic algae. In: Stevenson RG, Bothwell ML, Lowe RL (eds) Ecology of freshwater benthic algae. Academic Press, New York, p 341-374

Steinman AD, Mulholland PJ, Kirschtel DB (1991) Interactive effects of nutrient reduction and herbivory on biomass, taxonomic structure and P uptake in lotic periphyton communities. Can J Fish Aquat Sci 48:1951-1959

Swamikannu X, Hoagland KD (1989) Effects of snail grazing on the diversity and structure of a periphyton community in a eutrophic pond. Can J Fish Aquat Sci 46:1698-1704

Underwood AJ (1984) The vertical distribution and seasonal abundance of intertidal microalgae on a rocky shore in New South Wales. J Exp Mar Biol Ecol 78:199-220

Underwood AJ (1991) The logic of ecological experiments: a case history from studies of the distribution of macro-algae on rocky intertidal shores. J Mar Biol Assoc UK 71: 841-866

Underwood AJ, Denley EJ (1984) Paradigms, explanations, and generalizations in models for the structure of intertidal communities on rocky shores. In: Strong DR, Simberloff D, Abele LG, Thistle AB (eds) Ecoogical communities: conceptual issues and the evidence. Princeton University Press, Princeton, NJ, p 151-180

Williams GA, Davies MS, Nagarkar S (2000) Primary succession on a seasonal tropical rocky shore: relative roles of spatial heterogeneity and herbivory. Mar Ecol Prog Ser 203:81-94

Submitted: July 5, 2001, Accepted: February 5, 2002

Proofs received from author(s): May 6, 2002 